we showed that normal portions of such vegetables, if properly chosen and handled by the housewife, can adequately supply the full daily requirement of the vitamin.

We would emphasize these points in view of the economic importance of heated vegetables under existing conditions.

Chivers Laboratories,

Mamie Olliver.

Histon, Cambridge.

W. B. ADAM.

University of Bristol Research Station,

Campden, Glos.

\section{Effect of Flow on the Dielectric Constant of Liquids}

WE have observed that certain liquids, for example, xylene (a mixture of ortho-, para- and meta-), ethyl ether, ethyl alcohol and benzene show very small yet distinct decreases in the values of their dielectric constants when they are flowing through condenser plates of small separations. With a given separation the amount of change is found to increase with the rate of flow of the liquid. A typical graph showing the variations in the dielectric constant of a freshly distilled sample of xylene (a mixture of ortho-, paraand meta-) with flow under the pressure of different heights of the liquid is given in the accompanying graph. The temperature of the xylene remained practically constant at $24 \cdot 0^{\circ} \mathrm{C}$. throughout the experiment.

All the measurements for the dielectric constant were made by the usual heterodyne beat method using a wave-length of 300 metres. The experimental condenser consists of two horizontal circular brass plates; the lower one forms the main body of the apparatus, and the upper is separated from it by small, thin pieces of mica (thickness of the order of $0.01-$ $0.02 \mathrm{~cm}$.). The lower plate is provided with an opening at the centre which is connected by means of a U-tube to a long vertical glass tube of internal diameter $2 \cdot 4 \mathrm{~cm}$. The U-tube is fitted with a stopper. The upper plate is of diameter $8.6 \mathrm{~cm}$. and of thickness $0.6 \mathrm{~cm}$. and is fitted with a vertical rod at the centre. A load of about $10 \mathrm{kgm}$. is kept above the disk to prevent any mechanical displacement of the disk due to the hydrostatic pressure or flow of the liquids.

The condenser, the connecting tube and the vertical glass tube are filled with the liquid, and the flow of the latter commences as soon as the stopper is opened. The liquid rises through the central opening of the lower plate and after passing through the narrow space between the plates of the condenser comes out and is collected in a receiver. The level of the liquid in the vertical glass tube is kept constant by feeding the liquid at an adjusted rate from above. The changes in the capacity of the experimental condenser during flow are measured with the help of a specially designed condenser used by one of us ${ }^{1}$ in the measurement of the dielectric constant of an electron atmosphere. With this condenser changes so small as $0.004 \mu \mu \mathrm{F}$. can be measured.

Precautions were taken to see that changes observed in the capacity during the flow of the liquid were not due to any spurious effect such as mechanical displacement of disk or similar stray capacity changes. The entire experimental arrangement is enclosed in a case lined with tin which is connected to the earth; all adjustments are made from outside.

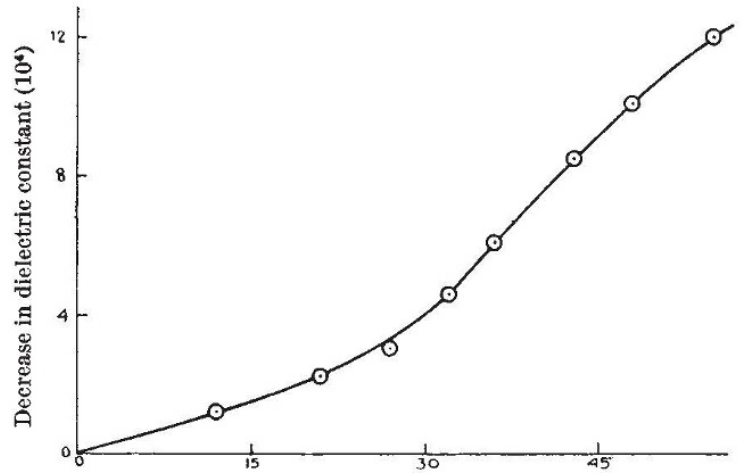

Height of xylene column (cm.)

Changes in the dielectric constant during flow are observed in polar as well as in non-polar liquids. But a more viscous liquid like amyl alcohol is found to show the effect to a much smaller degree. Observations with liquid heights greater than that shown in the graph could not be taken due to certain practical difficulties. Further investigations are, however, in progress and a detailed report will be published elsewhere.

We are grateful to Principal K. Prosad for the keen interest he has taken in this work.

\section{S. P. Prasad \\ B. N. SINGH. \\ B. D. Singh.}

Physics Laboratory,

Science College,

Patna.

Feb. 24.

${ }^{1}$ Prasad, S. P., and Varma, M. N., Z. Phys., 99, 552 (1936).

\section{Kinetic Friction Coefficient}

THE ordinary static friction apparatus with one mass $m$ hanging over a pulley and connected to another mass $M$ resting on the friction board may be used to determine the kinetic coefficient. Let $m$ be more than sufficient just to move $M$, and let $h$ be the vertical height over which $m$ is allowed to accelerate $M$; then, if $x$ is the extra distance along the board traversed by $M$ before it is brought to rest by friction, the average coefficient is given by :

$$
\mu_{k}=\frac{m}{M+\frac{(M+m) r}{h}}
$$

By varying $m$ in order to get a range of speed, the following fairly consistent values were got :

$\begin{array}{ccc}M \text { (gm.) } & m \text { (gm.) } & \begin{array}{c}\text { Coefficient of } \\ \text { kinetic friction }\end{array} \\ 74 \cdot 4 & 42 \cdot 7 & 0 \cdot 33 \\ 74 \cdot 4 & 52 \cdot 7 & 0 \cdot 33 \\ 74 \cdot 4 & 62 \cdot 7 & 0 \cdot 32 \\ 74 \cdot 4 & 72 \cdot 7 & 0 \cdot 33 \\ 74 \cdot 4 & 82 \cdot 7 & 0 \cdot 36 \\ 74 \cdot 4 & 92 \cdot 7 & 0 \cdot 32 \\ 74 \cdot 4 & 102 \cdot 7 & 0 \cdot 32 \\ 74 \cdot 4 & 112 \cdot 7 & 0 \cdot 33 \\ 74 \cdot 4 & 122 \cdot 7 & 0 \cdot 33\end{array}$

It may be that the method is in use, but a search in our selection of books on practical physics has not disclosed it.

Barnato Joel Laboratories,

Sidney Russ.

The Middlesex Hospital, London, W.1. 